\title{
Effect of combinations of antiviral drugs on herpes simplex encephalitis
}

This article was published in the following Dove Press journal:

Drug Design, Development and Therapy

8 December 2009

Number of times this article has been viewed

\section{Bryan M Gebhardt' \\ Federico Focher ${ }^{2}$ \\ Richard Eberle ${ }^{3}$ \\ Andrzej Manikowski ${ }^{4}$ \\ George E Wright ${ }^{4}$}

'LSU Eye Center, Department of Ophthalmology, Louisiana State University Health Sciences Center, New Orleans, LA, USA; 'Istituto di Genetica Molecolare, Consiglio Nazionale delle Ricerche, Pavia, Italy; ${ }^{3}$ Department of Veterinary Pathobiology, Center for Veterinary Health Sciences, Oklahoma State University, Stillwater, OK, USA; ${ }^{4} \mathrm{GLSynthesis}$ Inc., Worcester, MA, USA
Correspondence: George EWright GLSynthesis Inc., One Innovation Drive, Worcester, MA 01605, USA

Tel +I 508754 6700, ext. 102 $\mathrm{Fax}+\mathrm{I} 5087547075$

Email george.wright@glsynthesis.com

\begin{abstract}
Phenylamino-6-oxo-9-(4-hydroxybutyl)purine (HBPG) is a thymidine kinase inhibitor that prevents encephalitic death in mice caused by herpes simplex virus (HSV) types 1 and 2, although its potency is somewhat less than that of acyclovir (ACV). The present study was undertaken to determine the effect of combinations of HBPG and either ACV, phosphonoformate (PFA), or cidofovir (CDF) against HSV encephalitis. BALB/c mice were given ocular infections with HSV-1 or HSV-2, and treated twice daily intraperitoneally for five days with HBPG, alone or in combination with ACV, PFA, or CDF. Animals were observed daily for up to 30 days, and the day of death of each was recorded. All of the combinations showed additivity, and the combination of $\mathrm{HBPG}+\mathrm{ACV}$ appeared to be synergistic, ie, protected more mice against HSV-1 encephalitis compared with each drug given alone. Delay of treatment with HBPG for up to two days was still effective in preventing HSV-2 encephalitis. The combination of the thymidine kinase inhibitor HBPG and the antiherpes drug ACV may have synergistic activity against HSV encephalitis. The development of a potent and safe combination therapy for the prevention and/or treatment of HSV infection of the central nervous system can improve the outcome of this infection in humans.
\end{abstract}

Keywords: antivirals, herpetic encephalitis

\section{Introduction}

The major mucocutaneous diseases caused by herpes simplex virus (HSV) in humans are well managed by existing antiviral drugs, but neonatal herpes and herpes encephalitis are not. ${ }^{1}$ The drug of choice in the latter diseases is intravenous acyclovir (ACV), and an alternative drug for ACV-resistant viruses is foscarnet (phosphonoformate [PFA]), but some mortality still occurs and considerable morbidity remains for survivors.

HSV encephalitis is the most common form of fatal encephalitis in the US. Reports of prevalance of HSV encephalitis ${ }^{2,3}$ suggest that it occurs from 1-2 per 100,000 persons per year in the US. A detailed survey by the Centers of Disease Control ${ }^{4}$ for the years 1988-1997 reported an average of 2,151 hospitalizations per year for confirmed HSV encephalitis. (This may be an underestimate, because the causes of $59.5 \%$ of 18,680 hospitalizations for encephalitis were not disclosed.) Herpetic encephalitis results in high mortality, and survivors are often severely handicapped.

Recent published estimates of the incidence of neonatal herpes range from one per 3,500-5,000 births ${ }^{3}$ to three per 10,000 births or 1,200 cases per year in the US. ${ }^{5}$ Often this results because of massive exposure of the neonate to virus (usually HSV type 2) shed in the birth canal. The infected newborn may experience localized skin and ocular lesions, viremia, and localized central nervous system lesion development, 
usually starting within six days of birth. If infection results in disseminated disease, central nervous system (CNS) disease occurs in up to $50 \%$ of the infants and can result in $75 \%$ mortality. For the survivors of CNS involvement, the outcome is bleak, with psychomotor retardation in $50 \%$ to $75 \%$ of the survivors.

Intravenous acyclovir (ACV) is the drug of choice for therapy of newborns with localized or disseminated HSV disease, although vidarabine and phosphonoformate (PFA) have also been used. Although these treatments have reduced mortality from encephalitis to $15 \%$, only $50 \%$ of survivors develop normally. ${ }^{3}$ Unfortunately the overall mortality for disseminated neonatal herpes remains very high $(40 \%$ to $65 \%$ ) regardless of present antiviral therapy. Clearly there is a need for a superior antiviral drug which enters the CNS and inhibits infection and related neurological sequellae.

Recently we reported that an inhibitor/substrate of HSV types 1 and 2 (HSV-1, HSV-2) thymidine kinases, viz. 2-phenylamino-9-(4-hydroxybutyl)-6-oxopurine (HBPG) demonstrated potent antiviral activity in experimental models of HSV reactivation and encephalitis in mice. ${ }^{6}$ The lack of activity of closely related analogs suggests the possibility that HBPG owes its antiherpetic activity in the animal models, at least in part, to its conversion to phosphate forms in vivo. We now report the unexpected finding of additivity and possible synergism between HBPG and antiherpes drugs against HSV encephalitis in mice, most significantly with ACV.

\section{Materials and methods \\ Materials}

HBPG was synthesized as described, ${ }^{7}$ and ACV and PFA were purchased from Sigma (St. Louis, MO). Cidofovir (CDF) was a gift from Gilead Sciences Inc. (Foster City, CA). The McKrae strain of HSV-1 was isolated by Dr. Kaufman (LSU Eye Center, New Orleans, LA) and the F strain of HSV-1 and G strain of HSV-2 were obtained from the American Type Culture Collection (Manassas, VA). All viruses were propagated and titered on Vero cells, and stored frozen until use.

\section{Encephalitis models}

Six-week-old BALB/c female mice were provided food and water ad libitum and were maintained in an AAALAC accredited animal care facility.

\section{Ocular infection}

Mice were anesthetized by intraperitoneal (IP) injection of ketamine $(200 \mathrm{mg} / \mathrm{kg})$ and xylazine $(20 \mathrm{mg} / \mathrm{kg})$, their corneas lightly scratched with a 27 gauge needle, and $1 \times 10^{5}$ plaque-forming units (PFU) of infectious virus were dropped on each cornea. ${ }^{8}$ The animals were returned to their cages to recover from anesthesia.

\section{Intranasal infection}

Mice were anesthetized as above and infected with $2 \times 10^{5}$ PFU of infectious virus. Using a sterile pipet tip loaded with $10 \mu \mathrm{L}$ of the virus suspension, the liquid was deposited intranasally by gently inserting the pipet tip into the nasal opening and expelling the virus. ${ }^{8}$ The animals were returned to their cages to recover from anesthesia.

\section{Drug treatment}

Immediately following the infection and recovery from anesthesia, groups of 10 animals were given $0.1 \mathrm{~mL}$ IP injections of suspensions of test compounds in corn oil at the indicated dose or corn oil vehicle alone. Treatments were typically continued twice daily for five days, at 12-hour intervals (at 7 am and $7 \mathrm{pm}$ ). Animals were observed daily for a total of 30 days, and the day of death of each animal recorded. Plotting of survival vs dose gave the $\mathrm{ED}_{50}$ (the concentration of active compound that inhibited plaque formation by $50 \%$ ) values in Table $1 ; \mathrm{ED}_{50}$ is the individual dose that protected half of the animals.

\section{Statistical analysis}

Results of treatment groups were compared to controls for significance by the Fisher's exact test. Mean day of death (MDD) was calculated for each treatment group and compared to controls for significance by the Mann-Whitney $U$ test.

\section{Plaque reduction assays}

Virus stocks were diluted in cold Dulbecco's modified Eagle's medium (DMEM) containing 2\% fetal bovine serum (FBS), and six-well trays containing confluent monolayers of Vero cells were infected with $200 \mu \mathrm{L} /$ well of virus (to yield 150-250 PFU/well). Test compounds were dissolved in

Table I $\mathrm{ED}_{50} \mathrm{~s}$ of single drugs vs HSV encephalitis in mice

\begin{tabular}{lll}
\hline Drug & $E^{2}, \mathbf{m g} / \mathbf{k g}^{\mathrm{b}}$ & \\
\cline { 2 - 3 } & HSV-I & HSV-2 \\
\hline ACV & 82 & 90 \\
PFA & 200 & 300 \\
cidofovir & 3.2 & 2.4 \\
HBPG & 150 & 103 \\
\hline
\end{tabular}

Notes: ${ }^{\mathrm{a}}$ Ocular infection with HSV-I or HSV-2. ${ }^{\mathrm{b}}$ Treatment begun immediately after infection and continued twice daily (every 12 hours) IP for five days, in corn oil. Abbreviations: ACV, acyclovir;HBPG, 2-phenylamino-6-oxo-9-(4-hydroxybutyl)purine; HSV, herpes simplex virus; IP intraperitoneal; PFA, phosphonoformate. 
dimethyl sulfoxide (DMSO) at $10 \mathrm{mg} / \mathrm{mL}$, and diluted in overlay medium (DMEM containing 2\% FBS and $0.25 \%$ methylcellulose) singly or in combination. After one hour of adsorption at $37^{\circ} \mathrm{C}$, the viral inoculum was removed, and cells were overlaid with $2.5 \mathrm{~mL}$ of medium. Each test compound concentration or combination was tested in duplicate wells. Plates were incubated at $37^{\circ} \mathrm{C}$ for $36-48$ hours, and plaques were counted. The percent plaque reduction was calculated based on the number of plaques obtained in the absence of drugs. Antiviral activity is expressed as $\mathrm{EC}_{50}$.

\section{Results}

Various routes of infection have been used to establish HSV encephalitis in mice, including intranasal, ${ }^{9}$ intracerebral and IP, ${ }^{10,11}$ and intracutaneous. ${ }^{12}$ We used primarily ocular infection (see below) for comparison of drug-drug combination efficacy. Mean days of death after infection (MDD) in untreated animals were usually 9-10 with HSV-1 and 11-12 with HSV-2 infections. For comparison, in one experiment we used intranasal infection in which the MDDs for HSV-1 and HSV-2 were 9.1 and 9.9 days, respectively.

\section{Effect of single drugs on HSV encephalitis}

The standard treatment regimen of twice daily IP injections of compounds in corn oil suspensions for five days beginning immediately after recovery from anesthesia was used to compare efficacy of individual drugs. The antiherpes drugs PFA, ACV, and CDF and the experimental compound HBPG protected animals from HSV-1 and/or HSV-2 encephalitic death following infection by the ocular route in a dose dependent manner. The $\mathrm{ED}_{50}$ values (Table 1) show that CDF is by far the most effective drug, and that ACV and PFA have potencies within about twofold of each other. These results are consistent with reported activity of the drugs on HSV encephalitis in mice (see DeClercq and Holý). ${ }^{12} \mathrm{HBPG}^{6}$ was effective against both HSV-1 and HSV-2 encephalitis, and was intermediate in potency compared with ACV and PFA. Infections with HSV-1 or HSV-2 by the intranasal route were equiresponsive to the same regimens of $\mathrm{HBPG}$ and $\mathrm{CDF}$ (data not shown).

\section{Delay of treatment}

To compare the ability of HBPG to prevent an infection and to treat an established infection, the efficacy of the typical regimen (IP twice daily for five days) against HSV-2 encephalitis was measured after initiating treatment one, two, and three days after infection. The results, depicted graphically in Figure 1, show that gradual loss of HBPG efficacy occurred, but that substantial protection remained even when treatment began two full days after infection.

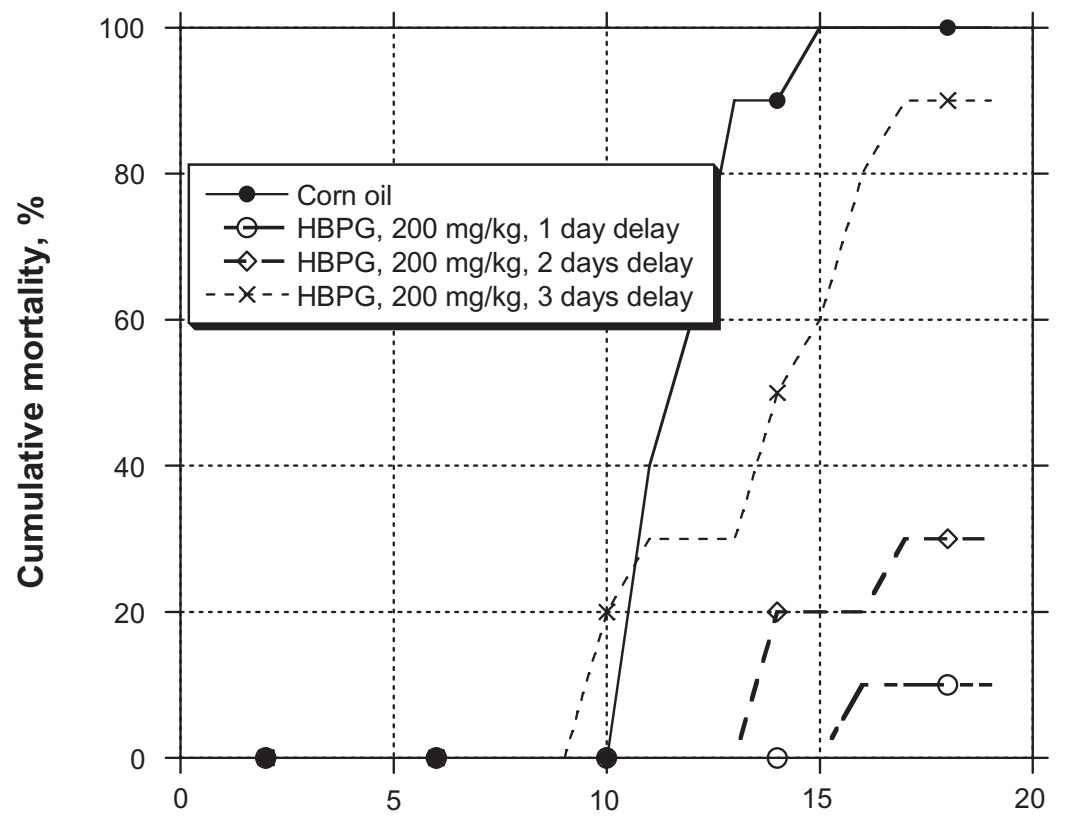

Days post infection

Figure I Efficacy of HBPG against HSV-2 encephalitis in mice after various delays in starting dosing post-infection. HBPG was given twice daily for five days. Notes: For reduction of mortality, $P<0.05$ at one and two days postinfection (Fisher's exact test). For MDD, $P<0.05$ at one and two days postinfection (Mann-Whitney $U$ test).

Abbreviations: HBPG, 2-phenylamino-6-oxo-9-(4-hydroxybutyl)purine; HSV, herpes simplex virus; MDD, mean day of death. 


\section{Effect of drug combinations on HSV encephalitis}

Combinations of HBPG with the standard antiherpes drugs increased survival of mice with HSV-1 and HSV-2 encephalitis over the expected results for simple additivity (Table 2). Using the $\mathrm{ED}_{50}$ values for each drug from Table 1 and the assumption of parallel dose-response curves, addition of the fractions of the $\mathrm{ED}_{50}$ of each was used to predict results of dosing of the combinations, assuming simple additivity of responses, ie, essentially a limited isobologram approach. ${ }^{13}$ Table 3 summarizes the results for several combinations. The results strongly suggest that HBPG and ACV are synergistic in their effect on HSV-1 encephalitis. For example, the expected survival of HSV-1-infected animals given $100 \mathrm{mg} / \mathrm{kg} \mathrm{HBPG}+50 \mathrm{mg} / \mathrm{kg}$ ACV was 64\%, but the combination gave $100 \%$ survival. HBPG and CDF also appeared synergistic against HSV-1, but not against HSV-2 encephalitis. No conclusions can be drawn about the combination of HBPG and PFA. Although suggestive, the data are insufficient to prove whether any combinations are synergistic or additive.

\section{Effect of the combination HBPG + ACV on HSV-I growth in proliferating cells}

The $\mathrm{EC}_{50}$ of $\mathrm{ACV}$ for plaque reduction in HSV-1 infected Vero cells (see Materials and methods) was $2.2 \mu \mathrm{g} / \mathrm{mL}$, and that of HBPG was $>100 \mu \mathrm{g} / \mathrm{mL}$. When $10 \mu \mathrm{g} / \mathrm{mL}$ of HBPG was present the apparent $\mathrm{EC}_{50}$ of $\mathrm{ACV}$ increased to $7.5 \mu \mathrm{g} / \mathrm{mL}$, suggesting antagonism of the antiviral effect. This result is consistent with observations for selective herpesvirus thymidine kinase inhibitors, which antagonize the activity of ACV in cell cultures (reviewed by Spadari and Wright). ${ }^{14}$ In contrast, the $\mathrm{EC}_{50}$ of PFA for plaque reduction in HSV-1 infected Vero cells was $20 \mu \mathrm{g} / \mathrm{mL}$ in the absence and $18 \mu \mathrm{g} / \mathrm{mL}$ in the presence of $10 \mu \mathrm{g} / \mathrm{mL}$ HBPG. PFA is a pyrophosphate analog that does not require activation by thymidine kinase. Thus the apparent synergism between ACV and HBPG against HSV encephalitis involves a completely different mechanism than inhibition of thymidine kinase.

\section{Discussion}

The thymidine kinase inhibitor/substrate HBPG was effective in protecting mice from death caused by infection with HSV-1 and HSV-2. The compound is intermediate in potency between ACV and PFA, the current drugs used to treat human cases of herpes encephalitis and neonatal herpes. The basis for activity of HBPG was first thought to involve inhibition of thymidine kinase in the CNS, given that neurons already contain low levels of precursors of DNA synthesis. Because HBPG is an efficient substrate for the viral $\mathrm{TK}^{6}$ it is also possible that the monophosphate or triphosphate of the compound is the active form. However, both the monophosphate and triphosphate of HBPG were weak inhibitors of the viral (HSV-1) DNA polymerase (Focher, unpublished observations) that is the target of nucleoside analogs as their triphosphates. If direct inhibition of thymidine kinase was the mechanism of antiencephalitic activity of HBPG, the compound would be expected to antagonize the activity of ACV. Indeed, this is just what is found in plaque reduction assays of HSV infected proliferating cells (see above and Spadari and Wright). ${ }^{14} \mathrm{HBPG}$, however, was

Table 2 Effect of drug combinations on HSV encephalitis in mice ${ }^{\mathrm{a}}$

\begin{tabular}{|c|c|c|c|c|c|}
\hline \multirow[t]{2}{*}{ HBPG dose, $\mathrm{mg} / \mathrm{kg}$} & \multirow[t]{2}{*}{ Drug, dose, mg/kg } & \multicolumn{2}{|l|}{ HSV-I } & \multicolumn{2}{|l|}{ HSV-2 } \\
\hline & & $\begin{array}{l}\text { Survivors/treated } \\
(P \text { value })^{\mathrm{d}}\end{array}$ & $\begin{array}{l}\text { MDD } \\
(P \text { value })^{\mathrm{e}}\end{array}$ & $\begin{array}{l}\text { Survivors/treated } \\
(P \text { value })^{\mathrm{d}}\end{array}$ & $\begin{array}{l}\text { MDD } \\
\text { ( } p \text { value) }\end{array}$ \\
\hline $0^{c}$ & $0^{c}$ & $0 / 10$ & 9.1 & $0 / 10$ & 13.7 \\
\hline 25 & PFA, 50 & nt & nt & $\mathrm{I} / \mathrm{IO}(P=0.5)$ & $14.3(p=0.14)$ \\
\hline 50 & & $\mathrm{nt}$ & $\mathrm{nt}$ & $9 / 20(P=0.012)$ & $13.3(p=0.4)$ \\
\hline 100 & $"$ & $\mathrm{nt}$ & nt & $8 / 10(P<0.001)$ & $15(p<0.05)$ \\
\hline 25 & ACV, 50 & $5 / 10(P=0.016)$ & $11.2(P=0.19)$ & nt & $\mathrm{nt}$ \\
\hline 50 & $"$ & $8 / 10(P<0.001)$ & $14(P=0.02)$ & nt & nt \\
\hline 100 & $"$ & $10 / 10(P<0.001)$ & na & nt & $\mathrm{nt}$ \\
\hline 25 & Cidofovir, 2.5 & $7 / 10(P=0.002)$ & $10.3(P<0.05)$ & $6 / 10(P=0.005)$ & $12(\mathrm{p}<0.05)$ \\
\hline 50 & $"$ & $9 / 10(P<0.001)$ & $10(P<0.05)$ & $10 / 10(P<0.001)$ & - \\
\hline 100 & $"$ & $10 / 10(P<0.001)$ & - & $10 / 10(P<0.001)$ & - \\
\hline
\end{tabular}

Notes: ${ }^{a}$ Animals were infected ocularly with HSV-I or HSV-2 and treated IP twice daily (every 12 hours) for five days with suspensions of drug combinations in corn oil or vehicle (corn oil) alone; 'bat 30 days; 'vehicle alone; 'Fisher's exact test; 'Mann-Whitney $U$ test.

Abbreviations: ACV, acyclovir; HBPG, 2-phenylamino-6-oxo-9-(4-hydroxybutyl)purine; HSV, herpes simplex virus; IP intraperitoneal; nt, not tested; PFA, phosphonoformate. 
Table 3 Effect of drug combinations ${ }^{\mathrm{a}}$ on survival rates from HSV encephalitis

\begin{tabular}{lll}
\hline Dose HBPG & \% Survivors & \\
\cline { 2 - 3 } & Calcd & Found
\end{tabular}

\begin{tabular}{llll}
\hline HSV-I, ACV + HBPG & & \\
Dose ACV & & & \\
50 & 25 & 39 & 50 \\
50 & 50 & 47 & 80 \\
50 & 100 & 64 & 100
\end{tabular}

$\begin{array}{ll}\text { HSV-I, CDF + HBPG } \\ \text { Dose CDF } \\ 2.5 & 25 \\ 2.5 & 50 \\ 2.5 & 100\end{array}$

\section{HSV-2, PFA + HBPG}

Dose PFA

$\begin{array}{llll}50 & 25 & 24 & 10 \\ 50 & 50 & 36 & 45 \\ 50 & 100 & 61 & 80\end{array}$

$\begin{array}{llll}\text { HSV-2, CDF + HBPG } & & \\ \text { Dose CDF } & & & \\ 2.5 & 25 & 64 & 60 \\ 2.5 & 50 & 76 & 100 \\ 2.5 & 100 & 100 & 100\end{array}$

Notes: a Dosing in $\mathrm{mg} / \mathrm{kg}$ twice daily for five days. ${ }^{\mathrm{b}} \mathrm{Calcd}$, calculated from the sum of survivors based on $\mathrm{ED}_{50}$ values (Table I) assuming additivity; Found, actual survival rate from combination treatment (Table 2).

Abbreviations: ACV, acyclovir; HSV, herpes simplex virus; HBPG, 2-phenylamino6-oxo-9-(4-hydroxybutyl)purine; CDF, cidofovir; PFA, phosphonoformate.

found unexpectedly to be additive or even synergistic with ACV against HSV-1 encephalitis (Tables 2 and 3), suggesting a mechanism of interaction in vivo that is different from simple antagonism expected of competitors for TK. Several studies have explored antiherpes combinations active against different viral targets. For example, a ribonucleotide reductase inhibitor potentiated activity of $\mathrm{ACV},{ }^{15}$ and docosanol was synergistic with various nucleoside analogs. ${ }^{16}$ These findings are consistent with the synergism observed when antiviral activities are directed against independent targets.

The treatment of HSV infection in the CNS requires that the drug reach this tissue at an effective concentration and in a timely manner. HSV infection of an epithelial surface, for example the nasal passages or the cornea, results in entry of the virus into the peripheral nervous system in two days and the CNS in three days. Exactly how many viral particles reach the CNS initially or how many rounds of viral replication are necessary to produce encephalitis is not known. Temporal studies with HBPG showed that 7 of 10 mice were protected from HSV-2 encephalitic death when treatment was begun two days after infection (Figure 1). In contrast, little efficacy of ACV was observed after a 24-hour ${ }^{17}$ or longer ${ }^{12}$ delay of treatment, and PFA showed a gradual loss of efficacy over a three day period postinfection. ${ }^{10}$ Only the phosphonate compound CDF prevented lethality of herpes encephalitis when treatment was delayed until four days postinfection. $^{12}$

The observation that HBPG exerts a protective effect two days after infection indicates that the drug penetrates the CNS in a therapeutically effective concentration and may reduce viral replication both before and after the development of encephalitis. Questions remaining to be answered include: Exactly how many viral particles reach the CNS? How much replication must occur to induce encephalitis? What is the concentration of HBPG in the CNS using the reported dose schedule? Is the combined drug therapy acting primarily outside the CNS? Is a significant component of the protection mediated in the CNS? Based on the disastrous consequences of CNS infection by HSV in encephalitis and neonates and our encouraging results indicating that mice can be protected against CNS infection by HBPG and a combination of HBPG and ACV, we believe that further study is warranted.

\section{Acknowledgments}

The authors are grateful for small business grant AI43170 from the National Institutes of Health (to GW), NIH Core grant P30EY002377 and an unrestricted departmental grant from Research to Prevent Blindness (both to LSU Eye Center), and by FIRB grant no. RBAU01LSR4_001 (to FF). The authors report no conflicts of interest in this work.

\section{References}

1. McGrath N, Anderson NE, Croxson MC, Powell KF. Herpes simplex encephalitis treated with acyclovir: diagnosis and long term outcome. J Neurol Neurosurg Psychiatry. 1997;63:321-326.

2. Whitley RJ. Viral encephalitis. New Engl J Med. 1990;323:242-250.

3. Whitley R, Lakeman F. Herpes simplex infections of the central nervous system: therapeutic and diagnostic considerations. Clin Infect Dis. 1995;20:414-420.

4. Khetsuriani N, Holman RC, Anderson LJ. Burden of encephalitisassociated hospitalizations in the United States, 1988-1997. Clin Infect Dis. 2002;35:175-182.

5. Lipsitch M, Davis G, Corey L. Potential benefits of a serodiagnostic test for herpes simplex virus type $1(\mathrm{HSV}-1)$ to prevent neonatal HSV-1 infection. Sex Transm Dis. 2003;29:399-405.

6. Manikowski A, Verri A, Lossani A, et al. Inhibition of herpes simplex virus thymidine kinases by 2-phenylamino-6-oxopurines and related compounds: Structure-activity relationships and antiherpetic activity in vivo. J Med Chem. 2005;48:3919-3929.

7. Xu H, Maga G, Focher F, et al. Synthesis, properties, and pharmacokinetic studies of $\mathrm{N}^{2}$-phenylguanine derivatives as inhibitors of herpes simplex virus thymidine kinases. J Med Chem. 1995;38:49-57. 
8. Gebhardt BM, Varnell ED, Hill JM, Kaufman HE. Animal models of ocular herpes simplex virus infection (rabbits, primates, mice). In: Handbook of Animal Models of Infection. Chapter 110. New York: NY Academic Press; 1999. p. 919-926.

9. DeClercq E, Luczak M. Intranasal challenge of mice with herpes simplex virus: An experimental model for evaluation of the efficacy of experimental drugs. J Infect Dis. 1976;133:A226-A236.

10. Kern ER, Glasgow LA, Overall Jr JC, Reno JM, Boezi JA. Treatment of experimental herpesvirus infections with phosphonoformate and some comparisons with phosphonoacetate. Amtimicrob Agents Chemother. 1978;14:817-823.

11. Kern ER, Richards JT, Overall Jr JC, Glasgow LA. Alteration of mortality and pathogenesis of three experimental herpesvirus hominis infections of mice with adenine arabinoside 5'-monophosphate, adenine arabinoside, and phosphonoacetic acid. Antimicrob Agents Chemother. 1978;13:53-60.

12. DeClercq E, Holý A. Efficacy of (S)-1-(3-hydroxy-2-phosphonylmethoxypropyl)-cytosine in various models of herpes simplex virus infection in mice. Antimicrob Agents Chemother. 1991;35:701-706.
13. Elion GB, Singer S, Hitchings GH. Antagonists of nucleic acid derivatives viii. synergism in combinations of biochemically related metabolites. J Biol Chem. 1954;208:477-488.

14. Spadari S, Wright G. Antivirals based on inhibition of herpesvirus thymidine kinases. Drug News Perspect. 1989;2:333-336.

15. Spector T, Harrington JA, Morrison Jr RW, et al. 2-Acetylpyridine 5-[(dimethylamino)thiocarbonyl]-thiocarbonohydrazone (A1110U), a potent inactivator of ribonucleotide reductases of herpes simplex and varicella-zoster viruses and a potentiator of acyclovir. Proc Natl Acad Sci US A. 1989;86:1051-1055.

16. Marcelletti JF. Synergistic inhibition of herpesvirus replication by docosanol and antiviral nucleoside analogs. Antivir Res. 2002;56:153-166.

17. Cho CT, Feng KK. Combined effects of acycloguanosine and humoral antibodies in experimental encephalitis due to Herpesvirus hominis. J Infect Dis. 1980;142:451.

\section{Publish your work in this journal}

Drug Design, Development and Therapy is an international, peerreviewed open-access journal that spans the spectrum of drug design and development through to clinical applications. Clinical outcomes, patient safety, and programs for the development and effective, safe, and sustained use of medicines are a feature of the journal, which has also been accepted for indexing on PubMed Central. The manuscript management system is completely online and includes a very quick and fair peer-review system, which is all easy to use. Visit http://www.dovepress.com/testimonials.php to read real quotes from published authors.

\footnotetext{
Submit your manuscript here: http://www.dovepress.com/drug-design-development-and-therapy-journal
} 